\title{
Intercellular adhesion molecule 1 is a sensitive and diagnostically useful immunohistochemical marker of papillary thyroid cancer (PTC) and of PTC-like nuclear alterations in Hashimoto's thyroiditis
}

\author{
KE ZHANG $^{1^{*}}$, SHU-JIAN GE ${ }^{2^{*}}$, XIAO-YAN LIN ${ }^{3}$, BEI-BEI LV ${ }^{3}$, ZHI-XIN CAO ${ }^{3}$, \\ JIA-MEI LI ${ }^{3}$, JIA-WEN XU ${ }^{3}$ and QIANG-XIU WANG ${ }^{3}$ \\ Departments of ${ }^{1}$ Nuclear Medicine, ${ }^{2}$ Science and Education and ${ }^{3}$ Pathology, \\ Shandong Provincial Hospital Affiliated to Shandong University, Jinan, Shandong 250021, P.R. China
}

Received November 21, 2014; Accepted November 23, 2015

DOI: $10.3892 / 01.2016 .4104$

\begin{abstract}
Intercellular adhesion molecule 1 (ICAM-1) is important in the progression of inflammatory responses. Recently, increased levels of ICAM-1 have been reported in a number of types of malignancy. The present study aimed to investigate ICAM-1 expression in papillary thyroid cancer (PTC) and in Hashimoto's thyroiditis (HT) with PTC-like nuclear alterations, and to assess the predictive value of ICAM-1 in thyroid lesions. ICAM-1 expression was retrospectively investigated in 132 consecutive cases of PTC, 72 cases of HT, 10 of follicular cancer, 15 of follicular adenoma, 16 of nodular goiter and 8 samples of normal thyroid tissue using immunohistochemical analyses, and in 42 PTC patients using western blotting. ICAM-1 expression was not detected in normal follicular cells, follicular lesions (adenoma and cancer) and benign nodular hyperplasia, but was frequently overexpressed in PTC cells. ICAM-1 overexpression was associated with extra-thyroidal invasion and lymph node metastasis; no association was found with age, gender, tumor size, multifocality, pathological stage, recurrence or distant metastasis. ICAM-1 expression in HT patients with PTC-like nuclear alterations was significantly higher than that in HT cases with non-PTC-like features. Compared with antibodies
\end{abstract}

Correspondence to: Dr Jia-Wen Xu or Professor Qiang-Xiu Wang, Department of Pathology, Shandong Provincial Hospital Affiliated to Shandong University, 324 Weiqi Avenue, Jingwu Road, Jinan, Shandong 250021, P.R. China

E-mail: mickypiero@aliyun.com

E-mail: wangqiangxiu@163.com

*Contributed equally

Key words: cytokeratin 19, galectin-3, Hashimoto's thyroiditis, Hector Battifora mesothelial-1, intercellular adhesion molecule 1, papillary thyroid cancer against cytokeratin 19, galectin-3 and Hector Battifora mesothelial-1, ICAM-1 was the most sensitive marker for the detection of PTC-like features in HT. These findings demonstrate that ICAM-1 expression is upregulated in PTC and in HT with PTC-like nuclear alterations. This feature may be an important factor in the progression of cancer of the thyroid gland.

\section{Introduction}

Papillary thyroid cancer (PTC) is the most prevalent type of malignant tumor of the endocrine system and accounts for $70-80 \%$ of all diagnosed cancers of the thyroid gland (1). Histopathological diagnosis of PTC is effective in the majority of cases. However, the diagnosis of rare variants of PTC and of Hashimoto's thyroiditis (HT) with PTC-like nuclear alterations is challenging.

Intercellular adhesion molecule 1 (ICAM-1) is a transmembrane glycoprotein receptor and a member of the immunoglobulin superfamily of adhesion molecules. It is expressed on the surface of various cell types, including endothelial cells, leukocytes (with the exception of basophilic granulocytes), T cells, B cells and fibroblasts. ICAM-1 is responsible for the arrest and transmigration of leukocytes out of blood vessels and into tissue, as well as the formation of immunological synapses during $\mathrm{T}$ cell activation (2). Recently, a number of studies have reported that ICAM-1 is present in several types of cancer, including prostate, breast and oral cancers (3-5), and is involved (at least in part) in their progression.

Few reports have found ICAM-1 expression to be elevated in PTC $(6,7)$, and the prognosis and clinical significance of ICAM-1 remain unclear, particularly in certain histological types of thyroid lesions (e.g., HT with PTC-like alterations). The present study sought to validate ICAM-1 as a sensitive immunohistochemical (IHC) marker to distinguish PTC from different diseases of the thyroid gland, and to estimate the predictive value of ICAM-1 by studying the aggressive behavior of PTC. 


\section{Materials and methods}

Ethical statement. The present study was approved by the Research Ethics Committee of Shandong Provincial Hospital Affiliated to Shandong University (Jinan, China) and written informed consent was obtained from all patients.

Clinical data. The study cohort comprised 245 consecutive patients (171 women and 74 men; age range, 28-75 years; mean age, 42 years). Of these, 132 had primary PTC, 10 had follicular cancer, 15 had follicular adenoma, 72 had HT and 16 had nodular goiter. In addition, 8 normal thyroid tissue samples were taken from the contralateral lobe of thyroid specimens containing cancer. None of the patients received medication prior to surgery. All underwent total thyroidectomy or lobectomy in the Department of Thyroid Surgery, Shandong Provincial Hospital, Shandong University, between January 2007 and December 2011. The pathological diagnoses of all specimens were graded according to the classification of thyroid malignancy by the World Health Organization (2004) (8) by two experienced pathologists.

For all patients, data were collected by retrospective review of medical records for gender, age, tumor size, extra-thyroidal invasion, pathological stage, lymph node status, focality, recurrence and distant metastatic dissemination. Tumors were staged according to the 7th edition of the tumor-node-metastasis-based staging system recommended by the American Joint Committee on Cancer and Union for International Cancer Control (9).

Antibodies for IHC analyses. Rabbit polyclonal antibodies against ICAM-1 (cat. no. sc-7891; dilution, 1:100) and galectin-3 (cat. no. sc-20157; dilution, 1:100) were purchased from Santa Cruz Biotechnology, Inc., (Santa Cruz, CA, USA). Mouse monoclonal antibodies against cytokeratin 19 (CK-19; cat. no. IS615; dilution, 1:100), Hector Battifora mesothelial-1 (HBME-1; cat. no. M3505; dilution, 1:100) and thyroid peroxidase (TPO; cat. no. M7257; dilution, 1:200) were obtained from Dako (Carpinteria, CA, USA).

IHC procedure. Sections (thickness, $4 \mathrm{~mm}$ ) were cut from formalin-fixed, paraffin-embedded blocks, and subsequently deparaffinized in xylene and rehydrated using a series of graded washes with ethanol. After inhibition of endogenous peroxidase and antigen retrieval (microwave irradiation in $0.01 \mathrm{M}$ citrate buffer at $\mathrm{pH} 6.0$ ), sections were incubated with each primary antibody at $4^{\circ} \mathrm{C}$ overnight, followed by incubation with horseradish peroxidase (HRP)-conjugated secondary antibodies (dilution, 1:1,00; Dako) for $1 \mathrm{~h}$ at $4^{\circ} \mathrm{C}$. Slides were developed for $5 \mathrm{~min}$ with the chromogen 3,3'-diaminobenzidine, counterstained with hematoxylin to distinguish the nucleus from the cytoplasm, and evaluated under a microscope (BX51; Olympus Corporation, Tokyo, Japan). Normal tonsil tissues (which are known to express ICAM-1) were used as positive and negative controls after being stained with or without primary antibodies, respectively. All assessments were undertaken in three separate experiments, and one representative assessment of three different experiments is shown.

Evaluation of stained samples. Immunostains were examined independently by two clinical pathologists. For ICAM-1, a staining value from 0 to 9 was calculated as the intensity of positive staining of the membrane or cytoplasm (negative, 0 ; weak, 1; moderate, 2; strong, 3) multiplied by the percentage of immunostained tumor cells $(\leq 10 \%, 1 ; 11-50 \%, 2 ; \geq 51 \%, 3)$. The intensity of staining was assessed in 100 cells. The final staining scores were classified according to the following scale: Value 0, score 0; values 1-2, score 1+; values 3-6, score $2+$; values $7-9$, score $3+$. All cases were divided into two groups of negative (score 0 or $1+$ ) and positive (score $2+$ or $3+$ ) expression.

Expression of galectin-3 in tumor cells was defined as 'positive' if cytoplasm was stained and occasional staining of the nucleus was also observed (10). Expression of CK-19 and HBME-1 was evaluated by staining of the cell membrane, and TPO by staining of the cytoplasm, respectively. The intensity of staining for each antibody was scored as follows: Negative, 0 ; weak, 1+; moderate, 2+; strong, 3+. Positive immunostaining was defined as a staining intensity of $2+$ to $3+$ in $>10 \%$ of cells. There were no differences in opinion between the two pathologists. All assessments were conducted in three separate experiments, and one representative assessment of three different experiments is shown.

Western blotting. Frozen tissues (100 mg) were collected from each sample and analyzed in modified radioimmunoprecipitation assay buffer (0.05 M Tris-HCl, $\mathrm{pH} 7.4 ; 1 \% \mathrm{NP}-40 ; 0.25 \%$ Na-deoxycholate; $0.15 \mathrm{M} \mathrm{NaCl} ; 0.001 \mathrm{M} \mathrm{Na}_{3} \mathrm{VO}_{4} ; 0.001 \mathrm{M}$ EDTA; and $0.5 \%$ of a protease inhibitor cocktail; Roche Diagnostics Operations, Indianapolis, IN, USA) chilled on ice for $30 \mathrm{~min}$ and centrifuged at $10,000 \mathrm{x} \mathrm{g}$ for $5 \mathrm{~min}$ at $4^{\circ} \mathrm{C}$. The resultant supernatant was collected and stored at $-70^{\circ} \mathrm{C}$. Protein concentration was determined using a Pierce ${ }^{\mathrm{TM}}$ bicinchoninic acid protein assay (Thermo Fisher Scientific, Rockford, IL, USA). Proteins were separated by $10 \%$ sodium dodecyl sulfate-polyacrylamide gel electrophoresis and transferred to polyvinylidene difluoride membranes (Millipore, Bedford, MA, USA). Following incubation in blocking buffer for $2 \mathrm{~h}$ at room temperature, incubation with rabbit anti-ICAM-1 polyclonal antibody (cat. no. sc-7891; dilution, 1:1,000; Santa Cruz Biotechnology, Inc.) and anti- $\beta$-actin antibody (cat. no. sc-130656; dilution, 1:1,000; Santa Cruz Biotechnology, Inc.) was conducted at $4{ }^{\circ} \mathrm{C}$ overnight, followed by incubation with HRP-conjugated goat anti-rabbit secondary antibody (Universal LSAB2 kit/HRP; dilution, 1:100; Dako) for $1 \mathrm{~h}$ at $4^{\circ} \mathrm{C}$. Western blot signals were visualized using a Pierce $^{\mathrm{TM}}$ enhanced chemiluminescent substrate (ECL Western Blotting Substrate; substrate, HRP; cat. no. 32106; Thermo Fisher Scientific) and quantified using a FluorChem Q Imaging System (Protein Simple, San Jose, CA, USA).

Statistical analyses. Data were analyzed by SPSS software version 16.0 (SPSS, Inc., Chicago, IL, USA). The $\chi^{2}$ test was used to calculate the statistical significance of the variables. $\mathrm{P}<0.05$ was considered to a indicate statistically significant difference.

\section{Results}

ICAM-1 expression in different diseases of the thyroid gland. Expression of ICAM-1 in 245 thyroid samples from patients 
Table I. ICAM-1 expression in different thyroid diseases by histopathology.

\begin{tabular}{lccc}
\hline & & \multicolumn{2}{c}{ ICAM-1 expression, $\mathrm{n}(\%)$} \\
\cline { 2 - 4 } Disease group & Patients, $\mathrm{n}$ & Positive & Negative \\
\hline PTC & 132 & $113(85.6)$ & $19(14.4)$ \\
Classic PTC & 107 & $95(72.0)$ & $12(9.1)$ \\
Follicular variant of PTC & 14 & $10(7.6)$ & $4(3.0)$ \\
Other variants of PTC & 11 & $8(6.0)$ & $3(2.3)$ \\
Hashimoto's thyroiditis & 72 & $22(30.1)$ & $50(69.9)$ \\
Follicular carcinoma & 10 & $0(0.0)$ & $6(100)$ \\
Follicular adenoma & 15 & $0(0.0)$ & $100(100)$ \\
Nodular goiter & 16 & $0(0.0)$ & $8(100)$ \\
Normal thyroid & 8 & $0(0.0)$ & $<0.001^{\mathrm{b}}$ \\
\hline
\end{tabular}

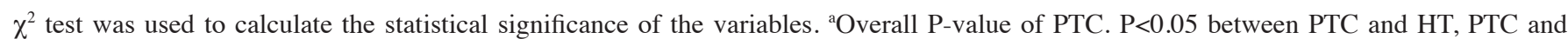
follicular carcinoma, PTC and follicular adenoma, PTC and nodular goiter and PTC and normal thyroid, individually. ${ }^{\mathrm{b} O v e r a l l ~ P-v a l u e ~ o f ~ H T C . ~}$ $\mathrm{P}<0.05$ between HT and follicular carcinoma, HT and follicular adenoma, HT and nodular goiter and HT and normal thyroid, individually. ICAM-1, intercellular adhesion molecule 1; PTC, papillary thyroid cancer.

who underwent surgery of the thyroid gland were investigated by IHC analyses. This revealed that $85.6 \%$ (113/132) of PTC samples and $18.1 \%(13 / 72)$ of HT samples were positive for ICAM-1, whereas all samples of follicular cancer $(n=10)$, follicular adenoma $(n=15)$, nodular goiter $(n=16)$ and normal thyroid $(n=8)$ were negative (Table I). As shown in Fig. 1, ICAM-1 expression was observed in the cell membrane and cytoplasm. Notably, in well-differentiated PTC tissues, ICAM-1 expression was detected at the apical surface of the papillary region and the thyroid gland (Fig. 1B-C). Expression of ICAM-1 was increased significantly in the PTC group compared with the other groups $(\mathrm{P}<0.001)$, and was also markedly higher in the HT group than in the other groups, with the exception of the PTC group $(\mathrm{P}<0.001)$.

ICAM-1 expression in PTC assessed using western blotting. In 42 PTC samples and paired non-tumorous thyroid tissue obtained from the same patients, ICAM-1 overexpression was found in 36 PTC samples in comparison with non-tumorous tissues $(\mathrm{P}<0.001)$ (Fig. 2). Western blotting results for ICAM-1 corroborated the immunostaining data (in which 34 of the corresponding 42 samples demonstrated positive immunostaining), and the agreement with IHC results was $94.4 \%$ (data not shown).

Association between ICAM-1 expression and clinicopathologic features of PTC. The associations between ICAM-1 expression and clinicopathological features of patients are shown in Table II. ICAM-1 expression was not correlated with age, gender, tumor size, multifocality, pathological stage, recurrence or distant metastasis $(\mathrm{P}>0.05)$. However, ICAM-1 expression was associated with extra-thyroidal invasion $(\mathrm{P}=0.015)$ and lymph node metastasis ( $\mathrm{LNM} ; \mathrm{P}=0.027)$. Of the 132 PTC patients, 47 had metastasis in the cervical lymph nodes, 35 had local recurrence, and 17 had distant metastasis ( 8 with lung metastasis, 4 with brain metastasis and 5 with bone metastasis). High expression of ICAM-1 was detected in the tumor cells of the 4 patients who died of distant metastasis.

ICAM-1 expression in HT patients. Of the 72 HT cases, 22 exhibited ICAM-1 expression. Contralateral thyroid cancer was diagnosed in 5 of these cases at 8-63 months after surgery, and LNM was detected in 2 of these 5 patients. Of 50 ICAM-1-negative patients, only 4 had contralateral thyroid cancer, and LNM was detected in 1 patient. Among the HT cases, the HT-to-PTC progression rate of ICAM-1 positive patients was significantly higher than that of ICAM-1 negative patients (22.7 vs. 8\%). Of 72 HT cases, 21 exhibited PTC-like features, 13 of which were positive for ICAM-1. Only 9 patients expressed ICAM-1 out of 51 with non-PTC-like HT (Table III). Thus, ICAM-1 expression in patients with PTC-like HT was significantly higher than that of cases with non-PTC-like HT $(\mathrm{P}<0.001)$.

To evaluate the diagnostic value of ICAM-1 expression for the detection of PTC-like alterations, antibodies against CK-19, galectin-3, HBME-1 and TPO were employed. The HT was set to be investigated for PTC-nuclear change, and was confirmed on the hematoxylin and eosin slides as the 'golden criteria'. The specificity and sensitivity of different antibodies and antibody combinations were calculated (Fig. 3). Galectin-3 was the most specific (71.4\%) single antibody, whilst HBME-1 had the lowest specificity (38.1\%). ICAM-1 was the most sensitive marker for the diagnosis of PTC-like features (82.4\%). With respect to antibody combinations, co-expression of any two or three antibodies increased the specificity of the diagnosis of PTC-like features to $>70 \%$ (range, 71.4-85.7\%), with three panels being 85.7\% specific (CK-19/galectin-3; ICAM-1/CK-19/galectin-3; and CK-19/galectin-3/HBME-1); however, the sensitivity of the three antibody combinations was significantly lower than for a single antibody (Table IV). 

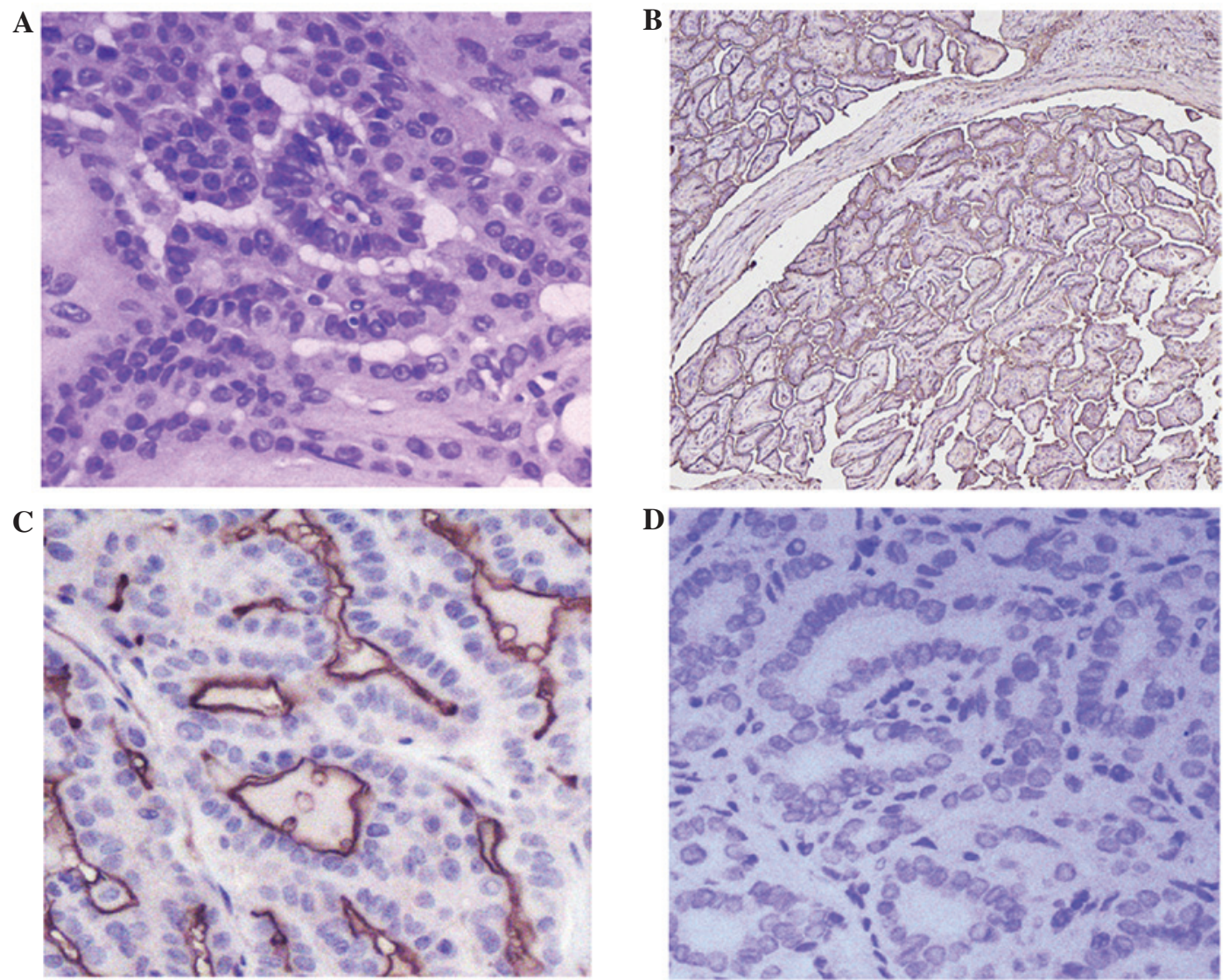

Figure 1. ICAM-1 expression in PTC tissue. (A) PTC (hematoxylin \& eosin stain; original magnification, x400). (B and C) Overexpression of ICAM-1 in PTC cells (immunostaining; original magnification, x100 and x400, respectively). (D) Thyroid peroxidase is not present in PTC cells (immunostaining; original magnification, x400). ICAM-1, intercellular adhesion molecule 1; PTC, papillary thyroid cancer.

\section{Discussion}

PTC is the most prevalent manifestation of cancer of the thyroid gland, representing $70-80 \%$ of all cancers of the thyroid gland (11). Examination by B-ultrasound has become the first choice for auxiliary examination of thyroid nodular disease, whilst pathological examination remains the 'gold standard' for the diagnosis of cancer (12). However, differentiating PTC from benign papillary hyperplasia of the thyroid gland based on its morphology (particularly if it exhibits PTC-like nuclear alterations) is challenging. Hence, identifying sensitive and specific IHC markers to differentiate between benign thyroid nodular disease and PTC is urgently required. CK-19, HBME-1 and galectin-3 have been demonstrated to show higher expression in PTC than in benign follicular lesions of the thyroid gland (13); however, results among studies have varied $(14,15)$. The present study assessed ICAM-1 expression and evaluated the diagnostic importance of PTC, as well as the potential value of measuring ICAM-1 expression in HT with PTC-like features.

In healthy individuals, ICAM-1 is expressed at low levels on various cell types, including endothelial cells, fibroblasts, and certain types of leukocyte (2). Recently, it has also been reported to play an important role in promoting progression in various types of cancer. Hayes and Seigel (2) observed ICAM-1 expression in 300 tissue cores from multiple arrays of normal, malignant and metastatic tissues by IHC analyses. They observed ICAM-1 expression to be associated with various cancer types, and it appeared to play a part in cancer metastasis (2). Several studies have demonstrated upregulation of ICAM-1 expression in PTC $(16,17)$. Buitrago et al (7) identified expression of the ICAM-1 gene to be higher in PTC and LNM when compared with benign tumors. In accordance with those results, 113 of 132 PTC samples exhibited overexpression of ICAM-1 in the present study, whereas no cases of follicular cancer, follicular adenoma, nodular goiter or normal thyroid tissues were immunoreactive. A constant diagnostic challenge occurs when differentiating the follicular variant of PTC from follicular lesions (adenoma and cancer). In the present study, 10 of 16 follicular-variant PTC cases exhibited moderate to high expression of ICAM-1, supporting the notion of ICAM-1 as a specific marker in differentiating between follicular-type lesions in thyroid tissues.

Furthermore, ICAM-1 expression was demonstrated to be associated with certain clinicopathological characteristics of patients. The growth pattern of the majority of PTC cases expressing ICAM-1 tended to have extra-thyroidal invasion and LNM, suggesting aggressive behavior. ICAM-1 has been demonstrated to facilitate the spread of metastatic cancer cells via the recruitment of inflammatory cells, by stimulating their proliferation, angiogenesis and invasion (18). However, the underlying mechanism of this action remains unclear.

The association between HT and PTC is controversial. The prevalence of cancer in HT has been reported to range from $<1$ to $32 \%$ (19-21). Jankovic et al (19) undertook a 
Table II. Correlation between clinicopathological features and ICAM-1 expression in papillary thyroid cancer patients ( $\mathrm{n}=132)$.

\begin{tabular}{|c|c|c|c|c|}
\hline \multirow[b]{2}{*}{ Variable } & \multirow[b]{2}{*}{ Patients, n (\%) } & \multicolumn{2}{|c|}{ ICAM-1 expression, n (\%) } & \multirow[b]{2}{*}{ P-value } \\
\hline & & Positive & Negative & \\
\hline Age, years & & & & 0.185 \\
\hline$\leq 40$ & $74(56.1)$ & $66(50.0)$ & $8(6.1)$ & \\
\hline$>40$ & $58(43.9)$ & $47(35.6)$ & $11(8.3)$ & \\
\hline Gender & & & & 0.402 \\
\hline Male & $38(28.8)$ & $31(23.5)$ & $7(5.3)$ & \\
\hline Female & $94(71.2)$ & $82(62.1)$ & $12(9.1)$ & \\
\hline Tumor size, $\mathrm{cm}$ & & & & 0.226 \\
\hline$\leq 1$ & $40(30.3)$ & $32(24.2)$ & $8(6.1)$ & \\
\hline$>1$ & $92(69.7)$ & $81(61.4)$ & $11(8.3)$ & \\
\hline pT stage & & & & 0.311 \\
\hline I & $38(28.8)$ & $34(25.8)$ & $4(3.0)$ & \\
\hline II & $74(56.1)$ & $64(48.5)$ & $10(7.6)$ & \\
\hline III & $20(15.1)$ & $15(11.4)$ & $5(3.8)$ & \\
\hline Extra-thyroid invasion & & & & $0.008^{\mathrm{a}}$ \\
\hline Yes & $72(54.5)$ & $67(50.8)$ & $5(3.8)$ & \\
\hline No & $60(45.5)$ & $46(34.8)$ & $14(10.6)$ & \\
\hline Multifocality & & & & 0.261 \\
\hline Yes & $41(31.1)$ & $33(25.0)$ & $8(6.1)$ & \\
\hline No & $91(68.9)$ & $80(60.6)$ & $11(8.3)$ & \\
\hline Lymph node metastasis & & & & $0.010^{\mathrm{a}}$ \\
\hline Yes & $47(35.6)$ & $45(34.1)$ & $2(1.5)$ & \\
\hline No & $85(64.4)$ & $68(51.5)$ & $17(12.9)$ & \\
\hline Recurrence & & & & 0.589 \\
\hline Yes & $35(26.5)$ & $29(22.0)$ & $6(4.5)$ & \\
\hline No & $97(73.5)$ & $84(63.6)$ & $13(9.8)$ & \\
\hline Distance & & & & 0.250 \\
\hline Yes & 17 (12.9) & $13(9.8)$ & $4(3.0)$ & \\
\hline No & $115(87.1)$ & $100(75.8)$ & $15(11.4)$ & \\
\hline
\end{tabular}

$\chi^{2}$ test was used to calculate the statistical significance of the variables. ${ }^{a} \mathrm{P}<0.05$. ICAM-1, intercellular adhesion molecule 1 .

systematic review of original studies that investigated the correlation between HT and PTC. Notably, studies based on fine-needle aspiration biopsy reported no link between HT and PTC, whereas many of the studies using thyroidectomy specimens revealed a positive association. Several authors have postulated that the inflammatory response may cause DNA mutations that eventually lead to the development of PTC $(22,23)$. Certain studies have observed a higher risk of PTC in patients with HT, particularly those who harbor focal PTC-like nuclear alterations in thyroid epithelial cells (e.g., nuclear overlapping, enlargement, chromatin clearing, intranuclear grooves and inclusions), which may be observed in almost one-third of HT cases on routine microscopic examination (24-26). A number of studies have reported that focal PTC-like changes suggest the possibility of focal, early premalignant transformation in some cases of HT, which eventually lead specifically to PTC $(27,28)$. It is likely that there is a morphological continuum between PTC-like thyrocytes,
Table III. ICAM-1 expression in Hashimoto's thyroiditis patients $(n=72)$.

\begin{tabular}{lrrr}
\hline & \multicolumn{2}{l}{ ICAM-1 expression, n (\%) } & \\
\cline { 2 - 3 } Group & Positive & Negative & P-value \\
\hline PTC-like & $13(18.1)$ & $8(11.1)$ & $<0.001^{\mathrm{a}}$ \\
Non-PTC-like & $9(12.5)$ & $42(58.3)$ & \\
\hline
\end{tabular}

$\chi^{2}$ test was used to calculate the statistical significance of the variables. ${ }^{\text {a }}<0.05$. PTC, papillary thyroid cancer.

follicular hyperplasia and metaplasia of Hürthle cells, and the reliability of valuable IHC markers is uncertain (29).

In this work, 21 of $72 \mathrm{HT}$ cases had features of PTC-like nuclear changes, most of which exhibited clusters and 


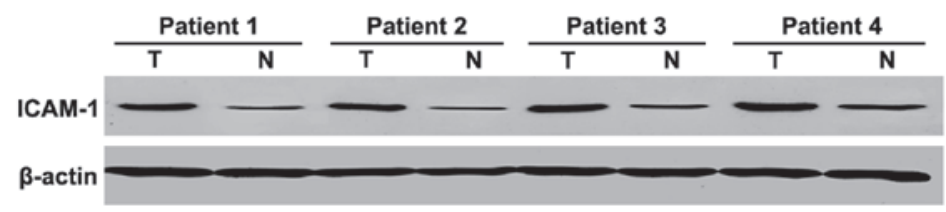

Figure 2. ICAM-1 expression assessed using western blotting in matched tumor $(\mathrm{T})$ and non-tumorous $(\mathrm{N})$ tissues obtained from PTC patients. Increased band intensities indicate significant upregulation of ICAM-1 expression in tumor tissue in comparison with that in non-tumorous tissue from the same patient. $\beta$-actin was used as a loading control to ensure equal amounts of protein in all lanes.

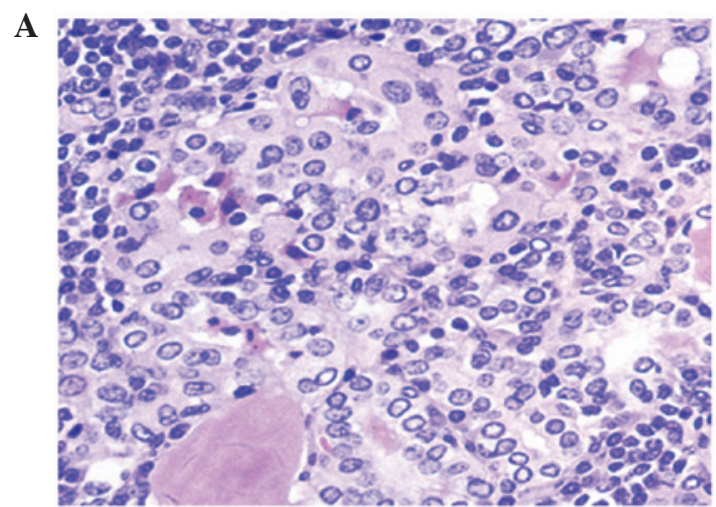

C

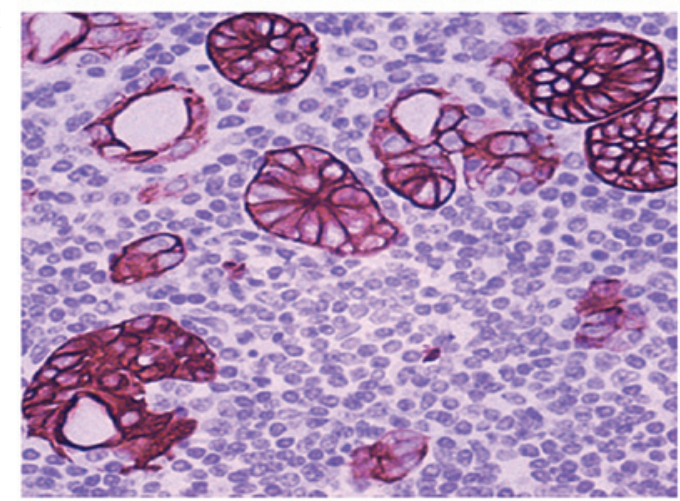

$\mathbf{E}$

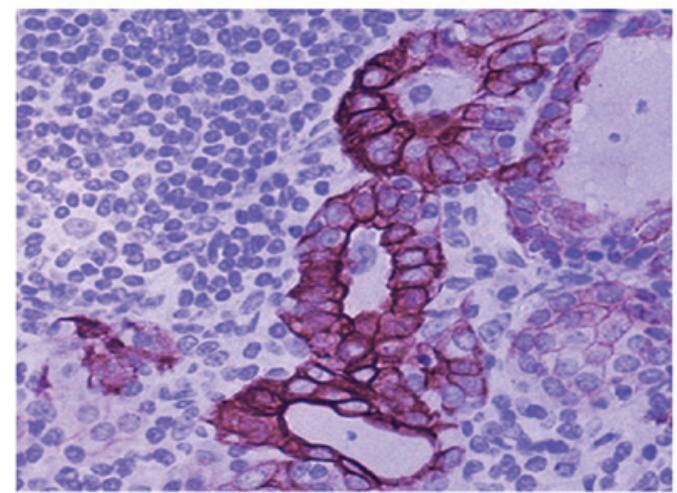

B

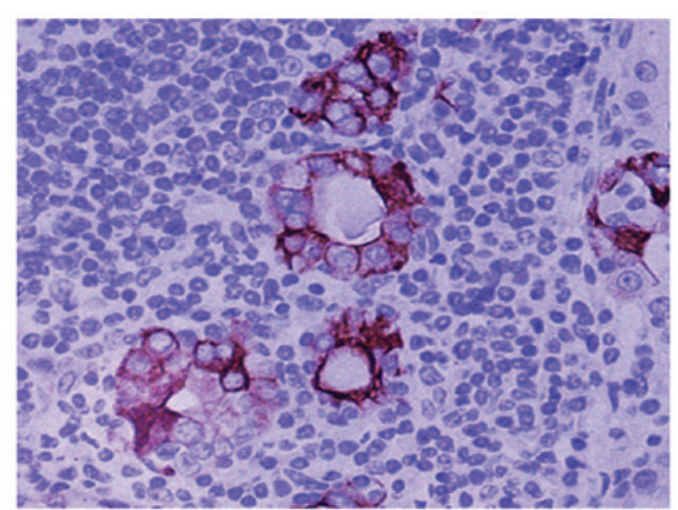

D

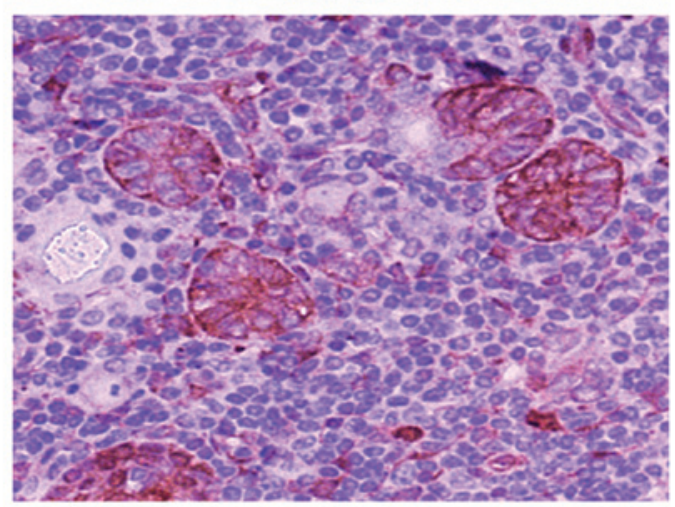

F

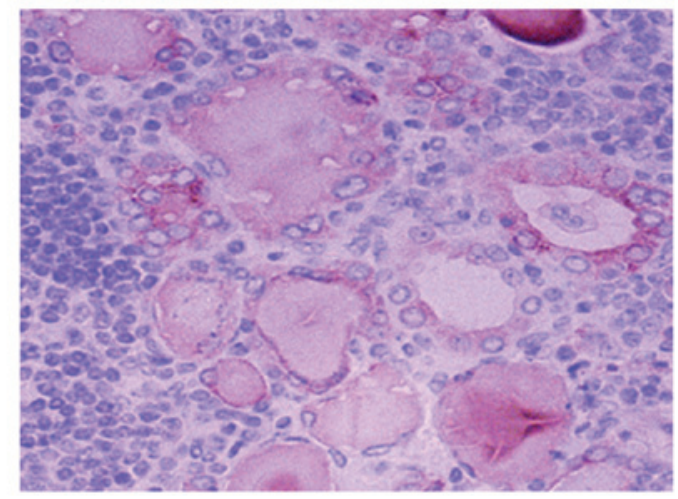

Figure 3. ICAM-1 expression in HT tissue with PTC-like nuclear alterations. (A) HT exhibiting an area of PTC-like nuclear changes (hematoxylin \& eosin stain; original magnification, x400). Expression of (B) ICAM-1, (C) cytokeratin 19, (D) galectin-3, (E) Hector Battifora mesothelial-1 and (F) thyroid peroxidase in thyrocytes with PTC-like nuclear alterations (immunostaining; original magnification, x400). ICAM-1, intercellular adhesion molecule 1; HT, Hashimoto's thyroiditis; PTC, papillary thyroid cancer.

micronodules that were histologically similar to PTC. Galectin-3, CK-19 and ICAM-1 exhibited high (71.4, 66.7 and $57.1 \%$, respectively) and diffuse expression. Comparatively, HBME-1 expression was lower (38.1\%), and was focused in thyrocytes with PTC-like nuclear changes. Prasad et al (24) noted focal expression of galectin-3 (87\%), CK-19 (65\%) and HBME-1 (26\%) primarily in nodules in HT cases, thereby demonstrating unique morphological features that overlap with PTC, in accordance with the current results. The utility of CK-19 expression has been studied extensively and it has been hypothesized to be the most sensitive marker for the diagnosis of PTC, and galectin-3 is also believed to be a valuable marker for distinguishing PTC from benign conditions (13). However, CK-19 was observed in $\sim 14 \%$ of cases of follicular adenoma, 
Table IV. Expression of four immunohistochemical markers in Hashimoto's thyroiditis patients $(\mathrm{n}=72)$.

\begin{tabular}{|c|c|c|c|c|c|c|}
\hline \multirow[b]{2}{*}{ Markers } & \multirow[b]{2}{*}{ Patients, $\mathrm{n}$} & \multicolumn{2}{|c|}{ Golden criteria, $\mathrm{n}$} & \multirow[b]{2}{*}{ P-value } & \multirow[b]{2}{*}{ Specificity, \% } & \multirow[b]{2}{*}{ Sensitivity, $\%$} \\
\hline & & Positive & Negative & & & \\
\hline ICAM-1 & & & & 1.000 & & \\
\hline Positive & 22 & 13 & 9 & & 61.9 & 82.4 \\
\hline Negative & 50 & 8 & 42 & & & \\
\hline CK-19 & & & & 0.071 & & \\
\hline Positive & 32 & 11 & 21 & & 52.4 & 58.8 \\
\hline Negative & 40 & 10 & 30 & & & \\
\hline GAL-3 & & & & 0.009 & & \\
\hline Positive & 35 & 15 & 20 & & 71.4 & 60.8 \\
\hline Negative & 37 & 6 & 31 & & & \\
\hline HBME-1 & & & & 1.000 & & \\
\hline Positive & 20 & 8 & 12 & & 38.1 & 76.5 \\
\hline Negative & 52 & 13 & 39 & & & \\
\hline ICAM-1/CK-19 & & & & $<0.001$ & & \\
\hline Positive & 43 & 16 & 27 & & 76.2 & 47.1 \\
\hline Negative & 29 & 5 & 24 & & & \\
\hline ICAM-1/GAL-3 & & & & $<0.001$ & & \\
\hline Positive & 44 & 17 & 27 & & 81.0 & 47.1 \\
\hline Negative & 28 & 4 & 24 & & & \\
\hline ICAM-1/HBME-1 & & & & 0.009 & & \\
\hline Positive & 35 & 15 & 20 & & 71.4 & 60.8 \\
\hline Negative & 37 & 6 & 31 & & & \\
\hline CK-19/GAL-3 & & & & $<0.001$ & & \\
\hline Positive & 51 & 18 & 33 & & 85.7 & 35.3 \\
\hline Negative & 21 & 3 & 18 & & & \\
\hline CK-19/HBME-1 & & & & 0.001 & & \\
\hline Positive & 39 & 15 & 24 & & 71.4 & 52.9 \\
\hline Negative & 33 & 6 & 27 & & & \\
\hline GAL-3/HBME-1 & & & & 0.001 & & \\
\hline Positive & 41 & 15 & 26 & & 71.4 & 49.0 \\
\hline Negative & 31 & 6 & 25 & & & \\
\hline ICAM-1/CK-19/GAL-3 & & & & $<0.001$ & & \\
\hline Positive & 55 & 18 & 37 & & 85.7 & 27.5 \\
\hline Negative & 17 & 3 & 14 & & & \\
\hline ICAM-1/CK-19/HBME-1 & & & & $<0.001$ & & \\
\hline Positive & 46 & 17 & 29 & & 81.0 & 43.1 \\
\hline Negative & 26 & 4 & 22 & & & \\
\hline ICAM-1/GAL-3/HBME-1 & & & & $<0.001$ & & \\
\hline Positive & 49 & 17 & 32 & & 81.0 & 37.3 \\
\hline Negative & 23 & 4 & 19 & & & \\
\hline CK-19/GAL-3/HBME-1 & & & & $<0.001$ & & \\
\hline Positive & 52 & 18 & 34 & & 85.7 & 33.3 \\
\hline Negative & 20 & 3 & 17 & & & \\
\hline
\end{tabular}

and galectin-3 could accumulate in inflammatory cells to react with the normal epithelium (13). Thus, CK-19 and galectin-3 may be less specific markers for the discrimination of benign changes from pre-malignant changes. How to best use these 
antibodies in routine practice (particularly if dealing with questionable PTC features) must be addressed fully.

The present study demonstrated ICAM-1 to be a sensitive IHC marker of PTC. Furthermore, positive staining with ICAM-1, if strong and diffuse, may be useful for distinguishing PTC-like alterations in HT from histological mimics. All 5 HT cases diagnosed with contralateral thyroid cancer following surgery were strongly positive for ICAM-1 expression, suggesting that ICAM-1 is a potential marker for predicting the possibility of progression to PTC in HT with PTC-like features. It was previously reported that expression of RET/PTC-1 and RET/PTC-3 oncogenes in patients with HT may identify HT as a pre-neoplastic lesion $(25,26)$. Reports have also stated that p63 protein $(30,31)$, and the loss of heterozygosity of 8-oxoguanine DNA glycosylase may be involved in neoplastic transformation from HT to PTC (32). To date, however, no affirmative genetic linkage has been confirmed. We suggest that ICAM-1 be used as part of a panel that may include CK-19 and galectin-3, depending on the differential diagnosis that is considered.

ICAM-1 appears to be a sensitive and diagnostically useful marker of PTC. Thus, it is proposed that ICAM-1 be used as part of a panel (and not in isolation) for the detection of PTC-like changes in thyrocytes in patients with HT. A statistically significant positive relationship between HT and PTC was not observed; however, careful observation and follow-up of HT patients is recommended (particularly for those with PTC-like alterations).

\section{Acknowledgements}

This research was supported by the Scientific Research Fund for the Health Development of Shandong Province, China (no. 2011HW053) and the National Nature Science Foundation for Young Scientists of China (no. 81202092).

\section{References}

1. Cheema Y, Repplinger D, Elson D and Chen H: Is tumor size the best predictor of outcome for papillary thyroid cancer? Ann Surg Oncol 13: 1524-1528, 2006.

2. Hayes SH and Seigel GM: Immunoreactivity of ICAM-1 in human tumors, metastases and normal tissues. Int J Clin Exp Pathol 2: 553-560, 2009.

3. Chen H, Hernandez W, Shriver MD, Ahaghotu CA and Kittles RA: ICAM gene cluster SNPs and prostate cancer risk in African Americans. Hum Genet 120: 69-76, 2006.

4. Rosette C, Roth RB, Oeth P, Braun A, Kammerer S, Ekblom J and Denissenko MF: Role of ICAM1 in invasion of human breast cancer cells. Carcinogenesis 26: 943-950, 2005.

5. Usami Y, Ishida K, Sato S, Kishino M, Kiryu M, Ogawa Y, Okura M, Fukuda Y and Toyosawa S: Intercellular adhesion molecule-1 (ICAM-1) expression correlates with oral cancer progression and induces macrophage/cancer cell adhesion. Int J Cancer 133: 568-578, 2013.

6. Nakashima M, Eguchi K, Ishikawa N, Yamashita I, Sakai M, Ida $\mathrm{H}$, Kawabe Y, Ito K and Nagataki S: Expression of adhesion molecule ICAM-1 (CD54) in thyroid papillary adenocarcinoma. J Endocrinol Invest 17: 843-848, 1994.

7. Buitrago D, Keutgen XM, Crowley M, Filicori F, Aldailami H, Hoda R, Liu YF, Hoda RS, Scognamiglio T, Jin M, et al: Intercellular adhesion molecule-1 (ICAM-1) is upregulated in aggressive papillary thyroid carcinoma. Ann Surg Oncol 19: 973-980, 2012.

8. DeLellis RA and Williams ED. Tumours of the thyroid and parathyroid. World Health Organization Classification of Tumours. Pathology and Genetics of Endocrine Organs. IARC Press, Lyon, pp58-70, 2004.
9. Edge SB and Compton CC: The American Joint Committee on Cancer: The 7th edition of the AJCC cancer staging manual and the future of TNM. Ann Surg Oncol 17: 1471-1474, 2010.

10. Cvejic D, Savin S, Petrovic I, Paunovic I, Tatic S, Krgovic K and Havelka M: Galectin-3 expression in papillary microcarcinoma of the thyroid. Histopathology 47: 209-214, 2005.

11. Cheema Y, Olson S, Elson D and Chen H: What is the biology and optimal treatment for papillary microcarcinoma of the thyroid? J Surg Res 134: 160-162, 2006.

12. Kabaker AS, Tublin ME, Nikiforov YE, Armstrong MJ, Hodak SP, Stang MT, McCoy KL, Carty SE and Yip L: Suspicious ultrasound characteristics predict BRAF V600Epositive papillary thyroid carcinoma. Thyroid 22: 585-589, 2012.

13. Scognamiglio T, Hyjek E, Kao J and Chen YT: Diagnostic usefulness of HBME1, galectin-3, CK19 and CITED1 and evaluation of their expression in encapsulated lesions with questionable features of papillary thyroid carcinoma. Am J Clin Pathol 126: 700-708, 2006.

14. El Demellawy D, Nasr A and Alowami S: Application of CD56, P63 and CK19 immunohistochemistry in the diagnosis of papillary carcinoma of the thyroid. Diagn Pathol 3: 5, 2008.

15. Rossi ED, Straccia P, Palumbo M, Stigliano E, Revelli L, Lombardi CP, Santeusanio G, Pontecorvi A and Fadda G: Diagnostic and prognostic role of HBME-1, galectin-3, and $\beta$-catenin in poorly differentiated and anaplastic thyroid carcinomas. Appl Immunohistochem Mol Morphol 21: 237-241, 2013.

16. Liu S, Li N, Yu X, Xiao X, Cheng K, Hu J, Wang J, Zhang D, Cheng $S$ and Liu S: Expression of intercellular adhesion molecule 1 by hepatocellular carcinoma stem cells and circulating tumor cells. Gastroenterology 144: 1031-1041, 2013.

17. Jenkinson C, Elliott V, Menon U, Apostolidou S, Fourkala OE, Gentry-Maharaj A, Pereira SP, Jacobs I, Cox TF, Greenhalf W, et al: Evaluation in pre-diagnosis samples discounts ICAM-1 and TIMP-1 as biomarkers for earlier diagnosis of pancreatic cancer. J Proteomics 113: 400-402, 2015.

18. Lin YC, Shun CT, Wu MS and Chen CC: A novel anticancer effect of thalidomide: Inhibition of intercellular adhesion molecule-1-mediated cell invasion and metastasis through suppression of nuclear factor-kappaB. Clin Cancer Res 12: 7165-7173, 2006.

19. Jankovic B, Le KT and Hershman JM: Clinical review: Hashimoto's thyroiditis and papillary thyroid carcinoma: Is there a correlation? J Clin Endocrinol Metab 98: 474-482, 2013.

20. Ahn D, Heo SJ, Park JH, Kim JH, Sohn JH, Park JY, Park SK and Park J: Clinical relationship between Hashimoto's thyroiditis and papillary thyroid cancer. Acta Oncol 50: 1228-1234, 2011.

21. Cheng V, Brainard J and Nasr C: Co-occurrence of papillary thyroid carcinoma and primary lymphoma of the thyroid in a patient with long-standing Hashimoto's thyroiditis. Thyroid 22: 647-650, 2012.

22. Tafani M, De Santis E, Coppola L, Perrone GA, Carnevale I, Russo A, Pucci B, Carpi A, Bizzarri M and Russo MA: Bridging hypoxia, inflammation and estrogen receptors in thyroid cancer progression. Biomed Pharmacother 68: 1-5, 2014.

23. Muzza M, Degl'Innocenti D, Colombo C, Perrino M, Ravasi E, Rossi S, Cirello V, Beck-Peccoz P, Borrello MG and Fugazzola L: The tight relationship between papillary thyroid cancer, autoimmunity and inflammation: Clinical and molecular studies. Clin Endocrinol (Oxf) 72: 702-708, 2010.

24. Prasad ML, Huang Y, Pellegata NS, de la Chapelle A and Kloos RT: Hashimoto's thyroiditis with papillary thyroid carcinoma (PTC)-like nuclear alterations express molecular markers of PTC. Histopathology 45: 39-46, 2004.

25. Sadow PM, Heinrich MC, Corless CL, Fletcher JA and Nose V: Absence of BRAF, NRAS, KRAS, HRAS mutations and RET/PTC gene rearrangements distinguishes dominant nodules in Hashimoto thyroiditis from papillary thyroid carcinomas. Endocr Pathol 21: 73-79, 2010.

26. Rhoden KJ, Unger K, Salvatore G, Yilmaz Y, Vovk V, Chiappetta G, Qumsiyeh MB, Rothstein JL, Fusco A, Santoro M, et al: RET/papillary thyroid cancer rearrangement in nonneoplastic thyrocytes: Follicular cells of Hashimoto's thyroiditis share low-level recombination events with a subset of papillary carcinoma. J Clin Endocrinol Metab 91: 2414-2423, 2006.

27. Lun Y, Wu X, Xia Q, Han Y, Zhang X, Liu Z, Wang F, Duan Z, Xin $\mathrm{S}$ and Zhang J: Hashimoto's thyroiditis as a risk factor of papillary thyroid cancer may improve cancer prognosis. Otolaryngol Head Neck Surg 148: 396-402, 2013. 
28. Konturek A, Barczyński M, Wierzchowski W, Stopa M and Nowak W: Coexistence of papillary thyroid cancer with Hashimoto thyroiditis. Langenbecks Arch Surg 398: 389-394, 2013.

29. Di Pasquale M, Rothstein JL and Palazzo JP: Pathologic features of Hashimoto's-associated papillary thyroid carcinomas. Hum Pathol 32: 24-30, 2001.

30. Unger P, Ewart M, Wang BY, Gan L, Kohtz DS and Burstein DE: Expression of p63 in papillary thyroid carcinoma and in Hashimoto's thyroiditis: A pathobiologic link? Hum Pathol 34: 764-769, 2003
31. Burstein DE, Nagi C, Wang BY and Unger $P$ : Immunohistochemical detection of p53 homolog p63 in solid cell nests, papillary thyroid carcinoma and hashimoto's thyroiditis: A stem cell hypothesis of papillary carcinoma oncogenesis. Hum Pathol 35: 465-473, 2004

32. Royer MC, Zhang H, Fan CY and Kokoska MS: Genetic alterations in papillary thyroid carcinoma and hashimoto thyroiditis: An analysis of hOGG1 loss of heterozygosity. Arch Otolaryngol Head Neck Surg 136: 240-242, 2010. 